\title{
Article \\ Use of Anti-Cytokine Therapy in Kidney Transplant Recipients with COVID-19
}

\author{
Marta Bodro ${ }^{1, *}$, Frederic Cofan ${ }^{2}$, Jose Ríos ${ }^{3}$, Sabina Herrera ${ }^{1}$, Laura Linares ${ }^{1}$, María Angeles Marcos ${ }^{4}$, \\ Alex Soriano ${ }^{1}{ }^{1}$, Asunción Moreno ${ }^{1}$ and Fritz Diekmann ${ }^{2}$
}

Citation: Bodro, M.; Cofan, F.; Ríos, J.; Herrera, S.; Linares, L.; Marcos, M.A.; Soriano, A.; Moreno, A.; Diekmann, F. Use of AntiCytokine Therapy in Kidney Transplant Recipients with COVID-19. J. Clin. Med. 2021, 10, 1551. https:// doi.org/10.3390/jcm10081551

Academic Editor: Frank Friedersdorff

Received: 12 February 2021

Accepted: 5 April 2021

Published: 7 April 2021

Publisher's Note: MDPI stays neutra with regard to jurisdictional claims in published maps and institutional affiliations.

Copyright: (c) 2021 by the authors. Licensee MDPI, Basel, Switzerland. This article is an open access article distributed under the terms and conditions of the Creative Commons Attribution (CC BY) license (https:/ / creativecommons.org/licenses/by/ $4.0 /)$.
1 Infectious Diseased Department, Institut d'Investigacions Biomèdiques August Pi i Sunyer (IDIBAPS), University of Barcelona and Hospital Clinic, 08036 Barcelona, Spain; sherrera@clinic.cat (S.H.); lalinares@clinic.cat (L.L.); asoriano@clinic.cat (A.S.); amoreno@clinic.cat (A.M.)

2 Department of Nephrology and Renal Transplantation, Institut d'Investigacions Biomèdiques August Pi i Sunyer (IDIBAPS), University of Barcelona and Hospital Clinic, 08036 Barcelona, Spain; fcofan@clinic.cat (F.C.); fdiekman@clinic.cat (F.D.)

3 Medical Statistics Core Facility, Biostatistics Unit, Faculty of Medicine, Universitat Autònoma de Barcelona, 08193 Bellaterra, Spain; jose.rios@uab.cat

4 Microbiology Department, Institut d'Investigacions Biomèdiques August Pi i Sunyer (IDIBAPS), University of Barcelona and Hospital Clinic, 08036 Barcelona, Spain; mmarcos@clinic.cat

* Correspondence: mbodro@clinic.cat

\begin{abstract}
In the context of the coronavirus disease 2019 (COVID-19) pandemic, we aimed to evaluate the impact of anti-cytokine therapies (AT) in kidney transplant recipients requiring hospitalization due to severe acute respiratory syndrome coronavirus 2 (SARS-CoV-2) infection. This is an observational retrospective study, which included patients from March to May 2020. An inverse probability of treatment weighting from a propensity score to receive AT was used in all statistical analyses, and we applied a bootstrap procedure in order to calculate an estimation of the 2.5th and 97.5th percentiles of odds ratio (OR). outcomes were measured using an ordinal scale determination (OSD). A total of 33 kidney recipients required hospitalization and $54 \%$ of them received at least one AT, mainly tocilizumab (42\%), followed by anakinra (12\%). There was no statistical effect in terms of intensive care unit (ICU) admission, respiratory secondary infections (35\% vs. $7 \%$ ) or mortality (16\% vs. $13 \%$ ) comparing patients that received AT with those who did not. Nevertheless, patients who received AT presented better outcomes during hospitalization in terms of OSD $\geq 5$ ((OR 0.31; 2.5th, 97.5th percentiles $(0.10 ; 0.72)$ ). These analyses indicate, as a plausible hypothesis, that the use of AT in kidney transplant recipients presenting with COVID-19 could be beneficial, even though multicenter randomized control trials using these therapies in transplanted patients are needed.
\end{abstract}

Keywords: COVID-19; kidney transplantation; anti-cytokine therapy; mortality; infection

\section{Introduction}

Severe acute respiratory syndrome coronavirus 2 (SARS-CoV-2) was first identified in December 2019 in Wuhan, China, and this novel coronavirus caused a national outbreak of severe pneumonia (coronavirus disease 2019 (COVID-19)) in China, rapidly spreading around the world thereafter, with more than 100,000,000 confirmed cases [1].

SARS-CoV-2 causes respiratory symptoms similar to those reported for SARS-CoV and Middle East Respiratory Syndrome Coronavirus (MERS-CoV). According to data from Wuhan local hospitals, and confirmed after in the rest of the world, the most common symptoms of COVID-19 were fever and dry cough at the onset of illness [2-4]. However, the most characteristic symptom of patients is respiratory distress, with many requiring intensive care management [2]. Moreover, accumulating evidence suggests that a subgroup of patients with severe COVID-19 have a cytokine storm syndrome, characterized by increased interleukin (IL)-1, IL-6, IL-7, interferon- $\gamma$ inducible protein 10 among others [3,5]. 
Importantly, host inflammatory responses appear to constitute an important cause of associated organ injury [5] and anti-cytokine therapies have been postulated as potential therapeutic options [6].

Some data have recently been published among solid organ transplant (SOT) recipients presenting with COVID-19 [7-12]. Nevertheless, information regarding use of biological therapies in this population is scarce and what is more, potential side effects of biologics are secondary infections, including opportunistic infections, which would add a pre-existing risk due to immunosuppressive therapy are lacking.

In this setting, we aimed to analyze kidney transplant recipients who required hospitalization due to COVID-19 and to evaluate the impact of anti-cytokine therapies on the outcomes.

\section{Materials and Methods}

From 6 March to 24 May, all kidney transplant recipients with respiratory symptoms and radiological evidence of pneumonia were admitted to the Hospital Clínic of Barcelona in the context of SARS-CoV-2 pandemic. Definitive diagnostic was established by a positive polymerase-chain reaction (PCR) from a nasopharyngeal swab. Clinical criteria for defining a case of SARS-CoV2 were the presence of respiratory symptoms with uni or bilateral interstitial infiltrates in the chest $X$ ray.

\subsection{Management of Coronavirus Disease 2019 (COVID-19)}

In the first instance, our hospital protocol consisted of lopinavir/ritonavir 400/100 mg twice a day (BID) for 7-14 days plus hydroxychloroquine $400 \mathrm{mg} / 12 \mathrm{~h}$ on the first day, followed by $200 \mathrm{mg} / 12 \mathrm{~h}$ for the next 4 days. From $18 \mathrm{March}$, azithromycin $500 \mathrm{mg}$ for $24 \mathrm{~h}$ and $250 \mathrm{mg} / 24 \mathrm{~h}$ for 4 additional days was added to the protocol. All patients with risk factors for thrombosis received prophylactic doses of low-weight heparin. The local indication for anti-cytokine therapy was restricted for patients with pneumonia, progressive respiratory failure (increasing fraction of inspired oxygen) and C-reactive protein (CRP) $\geq 8 \mathrm{mg} / \mathrm{dL}$ or ferritin $\geq 800 \mathrm{ng} / \mathrm{mL}$ or lymphocyte count $<800$ cells $/ \mathrm{mm}^{3}$. The choice of anti-cytokine therapy was taken at the discretion of the attending physician. The dose of tocilizumab was $400 \mathrm{mg} / 24 \mathrm{~h}$ iv for patients with $\leq 75 \mathrm{~kg}$ and $600 \mathrm{mg} / 24 \mathrm{~h}$ intravenous (iv) for those with $>75 \mathrm{~kg}$, patients with no improvement could receive additional doses every $12 \mathrm{~h}$ up to a maximum of 3 doses. The dose of anakinra was $200 \mathrm{mg} / 12 \mathrm{~h} \mathrm{sc}$ for $24 \mathrm{~h}$ and $200 \mathrm{mg} / 24 \mathrm{~h}$ with a maximum of 3 doses. The dose of baricitinib was $4 \mathrm{mg} / 24 \mathrm{~h}$ with a maximum of 4 doses. High doses of metilprednisolone $(250 \mathrm{mg} / 24 \mathrm{~h}$ for 3 days followed by $30 \mathrm{mg} / 24 \mathrm{~h}$ for 3 days) could be prescribed in patients presenting with poor outcomes despite receiving biologic therapy. Hepatitis B serologies (hepatitis B surface antigen) and QuantiFERON-TB ${ }^{\circledR}$ was performed prior to anti-cytokine prescription and prophylaxis with entecavir and isoniazid respectively were individually assessed. Secondary infections were defined as infections that occur during or after COVID-19. If they occurred $48 \mathrm{~h}$ after admission they were defined as hospital-acquired superinfections, whereas if they were diagnosed at the time of or within the first $24 \mathrm{~h}$ of hospital admission they were defined as community-acquired co-infections. We used the RIFLE criteria [13] (Risk, Injury, Failure, Loss, and End-stage kidney disease) to define impaired kidney graft function. Additionally, an increase in serum creatinine of 1.5-2 times, or a decrease in the glomerular filtration rate of more than $25 \%$ over baseline, was also considered in the definition of impaired kidney graft function.

\subsection{Management of Immunosuppressive Treatment}

According to our center's policy, due to the potential severity of SARS-CoV-2 infection, mycophenolate and mTOR inhibitor (sirolimus or everolimus) were initially withdrawn in all admitted kidney transplant recipients with COVID-19. Furthermore, in patients starting treatment with lopinavir/ritonavir, the calcineurin inhibitor (CNI) (tacrolimus or cyclosporine) was also temporarily discontinued due to the strong interactions resulting 
in the increase of $\mathrm{CNI}$ levels. Maintenance immunosuppression consisted of prednisone monotherapy (20 mg/day) until COVID-19 resolution, at which time tacrolimus was reinitiated at reduced doses (through blood levels around $5 \mathrm{ng} / \mathrm{mL}$ ).

\subsection{Ordinary Scale Determination (OSD)}

We used a clinical ordinary scale determination (OSD) to assess patient clinical status. This OSD was recorded at baseline and during hospitalization. The ordinal scale categories were: (1) Patients ready for discharge, (2) Patients requiring non-intensive care unit (ICU) hospital ward not requiring supplemental oxygen, (3) Patients requiring non-ICU hospital ward requiring supplemental oxygen, (4) Patients hospitalized in ICU or non-ICU hospital ward, requiring non-invasive ventilation or high-flow oxygen, (5) Patients hospitalized in ICU requiring intubation and mechanical ventilation, (6) Patients hospitalized in ICU, requiring extracorporeal membrane oxygenation (ECMO) or mechanical ventilation and additional organ support (e.g., vasopressors, renal replacement therapy) and (7) Death.

\subsection{Statistical Analysis}

Results are shown as median and interquartile range (IQR: 25th and 75th percentiles) or absolute frequencies and percentages for quantitative and qualitative variable respectively.

Probability of poor clinical outcome, defined as OSD $>=5$, was estimated by means the odds ratio (OR) and their $95 \%$ confidence intervals $(95 \% \mathrm{CI})$ from a weighted logistic regression models using the inverse of probability of treatment weighting (IPTW). This IPTW was used as a weight in order to create a synthetic sample with the distribution of covariates independent of biological prescription [14].

This IPTW was derived from a propensity score (PS) to receive biologic treatment from the following parameters: age, sex, number of comorbidities, basal creatinine, number of analytical values in last tercile, to establish high analytical alteration, prior transplantation, days from symptom onset to test, type of immunosuppressive regimen, baseline OSD and therapeutic effort limitation. Finally, this IPTW was stabilized by proportion of prescription to biological treatment.

We calculated standardized differences, as differences between groups divided by pooled standard deviation, to assess homogeneity between patients with biologic prescription or not in their baseline characteristics. After IPTW use, some authors consider the cut-off point for standardized differences to be at \pm 0.20 [15], in this study all covariates were well balanced with the exception of a baseline result of OSD $>2$, this particular misbalance is probably due to the fact that only one patient without biologic treatment had a baseline OSD $>2$.

A bootstrap resampling procedure with replacement, with a rate of $80 \%$, for 1000 samples, and a seed $=20200601$ (date of closure of the database) was conducted as a measure of complementary results, in order to estimated 2.5th and 97.5th percentiles of OR. Missing data imputation for D-dimer, C-reactive protein, lactate dehydrogenase (LDH), ferritin and lymphocytes count was undertaken using the expectation-maximization (EM) algorithm [16] which relies on the flexible and reasonable missing at random (MAR) assumption, using age, sex, therapeutic effort limitation, secondary infection, hypertension, diabetes, cardiopathy and pneumopathy as additional factors for imputation. The amount of imputed missing data was 3\% for D-dimer and lymphocytes, $9 \%$ for LDH and $12 \%$ for ferritin.

In all statistical analyses we applied a two-sided type I error of 5\%. SPSS v.25 (IBM) and SAS v9.4 (Cary, NC, USA) were used for the analysis.

\section{Results}

During the study period, 1742 patients were hospitalized due to COVID-19 in our hospital and 33 of them were kidney transplant recipients.

Baseline characteristics of kidney transplant recipients with SARS-CoV2 infection are described in Table 1. Sixty one percent of the kidney transplant recipients were male, and 
most of them had arterial hypertension (91\%) and received non-mTOR-inhibitor based regimen $(64 \%)$ (mainly tacrolimus-mycophenolic acid) and 36\% an mTOR-inhibitor based regimen (sirolimus or everolimus). Twenty-one percent of them had received a previous transplant, and none of them had a history of acute rejection episode in the preceding 3 months. Median time from transplantation to diagnosis was 5.5 years (IQR $0.5 ; 21$ ) and median time from symptom onset to positive test was 6 days (IQR 0; 20). Hydroxicloroquine was prescribed in $91 \%$ of patients, azithromycin in $85 \%$ and lopinavir/ritonavir in $82 \%$. Forty-two percent of patients received tocilizumab (14/33), 24\% high doses of steroids $(8 / 33), 18 \%$ anakinra $(6 / 33)$ and $3 \%$ baricitinib $(1 / 33)$. Three patients $(9 \%)$ received tocilizumab and anakinra. All patients were discharged at the end of the study period.

Table 1. Baseline characteristics of kidney transplant recipients hospitalized due to coronavirus disease 2019 (COVID).

\begin{tabular}{|c|c|}
\hline Variable & $\begin{array}{l}\text { Total } \\
n(\%)\end{array}$ \\
\hline Age, median, IQR & $55(33-86)$ \\
\hline Male sex & $20(61)$ \\
\hline Hypertension & $30(91)$ \\
\hline Diabetes mellitus & $9(27)$ \\
\hline Cardiopathy & $11(33)$ \\
\hline $\begin{array}{l}\text { Chronic obstructive pulmonary disease } \\
\text { Cause of end- stage kidney disease }\end{array}$ & $4(12)$ \\
\hline - Nephroangiosclerosis & $5(15)$ \\
\hline - Glomerulonephritis & $10(30)$ \\
\hline - Diabetes mellitus & $1(3)$ \\
\hline - Polycystic kidney disease & $6(18)$ \\
\hline - Ureteral reflux & $2(6)$ \\
\hline - Not diagnosed & $9(27)$ \\
\hline Prior transplantation & $7(21)$ \\
\hline Multivisceral transplantation & $2(6)$ \\
\hline Immunosupressive regimen & \\
\hline - Non mTOR based regimen & $21(64)$ \\
\hline - $\quad$ mTOR based regimen & $12(36)$ \\
\hline Acute allograft rejection (3 months prior) & 0 \\
\hline Years from transplant to diagnosis, median, IQR & $5.5(0.5-21)$ \\
\hline Presenting symptoms & \\
\hline - $\quad$ Fever & $29(91)$ \\
\hline - $\quad$ Fatigue & $3(9)$ \\
\hline - Hyposmia/ageusia & $3(9)$ \\
\hline - Cough & $18(56)$ \\
\hline - Diarrhea & $6(18)$ \\
\hline Days from symptom onset to test, median, IQR & $6(0-20)$ \\
\hline Serum basal creatinine $(\mathrm{mg} / \mathrm{dL}), \mathrm{IQR}$ & $1.4(0.8-3.7)$ \\
\hline Impaired kidney graft function & $17(52)$ \\
\hline Respiratory insufficiency & $21(64)$ \\
\hline ICU admission & $11(33)$ \\
\hline Invasive mechanical ventilation & $4(12)$ \\
\hline Maximum ferritin levels (ng/mL) (NR) 20-400 & $888(281-4372)$ \\
\hline Maximum C-reactive protein $(\mathrm{mg} / \mathrm{dL}) \mathrm{NR}<0.4$ & $14(0-25)$ \\
\hline Maximum Lactate dehydrogenase (U/L) NR $<234$ & $254(198-687)$ \\
\hline Minimum lymphocytes count $\left(1000 / \mathrm{mm}^{3}\right)$ & $600(100-1000)$ \\
\hline D-dimer $(\mathrm{ng} / \mathrm{mL}) \mathrm{NR}<500$ & $1300(500-12400)$ \\
\hline Secondary infection & $7(23)$ \\
\hline Median days of hospitalization (IQR) & $12(4-59)$ \\
\hline Overall mortality & $4(12)$ \\
\hline
\end{tabular}

Interquartile range (IQR); normal range (NR). 
Table 2 shows the description of baseline characteristics of patients stratified by biologic prescription and clinical presentation of kidney transplant recipients with COVID-19. Standardized differences showed baseline heterogeneity between both groups for number of analytical results in last tercile. Biologic treatment was prescribed more frequently in patients presenting with respiratory insufficiency compared with those with no respiratory insufficiency ( $74 \%$ vs. $26 \%$ ). Six patients required ICU admission in the biologic group $(33 \%)$. Two of these patients required ICU admission $>24 \mathrm{~h}$ after biologic infusion, but none of them required invasive mechanical ventilation. No immediate drug-related side effects such as severe neutropenia, thrombocytopenia or hepatitis were reported.

Table 2. Baseline characteristics and clinical presentation of kidney recipients with COVID-19 by biologic therapy prescription and standardized difference depending on before and after application of inverse of probability of treatment weighting (IPTW) in the comparison.

\begin{tabular}{|c|c|c|c|c|c|}
\hline \multirow[b]{2}{*}{ Age, median, IQR } & \multirow{2}{*}{$\begin{array}{c}\begin{array}{c}\text { Biologic } \\
(n=19)\end{array} \\
52(37 ; 83)\end{array}$} & \multirow{2}{*}{$\begin{array}{c}\begin{array}{c}\text { Non Biologic } \\
(n=14)\end{array} \\
61(33 ; 87)\end{array}$} & \multirow{2}{*}{$\begin{array}{c}p \text { Value } \\
0.4\end{array}$} & \multicolumn{2}{|c|}{$\begin{array}{c}\text { Standarized Difference } \\
\text { Raw } \\
\text { IPTW } \\
\text { Adjusted }\end{array}$} \\
\hline & & & & -0.070 & -0.141 \\
\hline Male sex & $11(61)$ & $9(60)$ & 1 & 0.131 & -0.080 \\
\hline Hypertension & $15(83)$ & $15(100)$ & 0.1 & & \\
\hline Diabetes mellitus & $5(28)$ & $4(27)$ & 1 & & \\
\hline Cardiopathy & $6(33)$ & $5(33)$ & 1 & & \\
\hline $\begin{array}{l}\text { Chronic obstructive pulmonary } \\
\text { disease }\end{array}$ & $4(22)$ & 0 & 0.1 & & \\
\hline $\begin{array}{l}\text { Number of comorbidities, } \\
\text { median(IQR) }\end{array}$ & $1(0 ; 4)$ & $1.5(1 ; 3)$ & 0.6 & 0.197 & 0.158 \\
\hline Prior transplantation & $4(22)$ & $3(20)$ & 1 & -0.009 & 0.033 \\
\hline $\begin{array}{l}\text { Multivisceral transplantation } \\
\text { Immunosupressive regimen }\end{array}$ & $2(11)$ & 0 & 0.5 & & \\
\hline $\begin{array}{l}\text { - Non-mTOR-inhibitor based } \\
\text { mTOR-inhibitor based }\end{array}$ & $\begin{array}{c}11 \\
7\end{array}$ & $\begin{array}{c}10 \\
5\end{array}$ & 1 & 0.0235 & -0.034 \\
\hline $\begin{array}{l}\text { Years from transplant to diagnosis, } \\
\text { median (IQR) }\end{array}$ & $4.8(0.5 ; 15.5)$ & $6.2(0.5 ; 21.6)$ & 0.4 & & \\
\hline $\begin{array}{l}\text { Days from symptom onset to test, } \\
\text { median (IQR) }\end{array}$ & $6(1 ; 20)$ & $6(2 ; 15)$ & 0.7 & & \\
\hline Days from symptom onset to test $<7$ & $6(31.6)$ & $4(28.6)$ & & -0.009 & 0.0326 \\
\hline Baseline OSD, median, IQR & $2(2 ; 4)$ & $2(2 ; 5)$ & 0.09 & & \\
\hline Baseline OSD >2 (needed $\mathrm{O}_{2}$ ) & $6(31.6)$ & $1(7.1)$ & & 0.6503 & 0.3035 \\
\hline $\begin{array}{l}\text { OSD during hospitalization, } \\
\text { median, IQR }\end{array}$ & $3(2 ; 6)$ & $2(2 ; 5)$ & 0.004 & & \\
\hline Serum basal creatinine & $1.5(0.8 ; 3.4)$ & $1.3(0.8 ; 3.7)$ & 0.3 & 0.2311 & 0.0457 \\
\hline Impaired kidney graft function & $11(58)$ & $6(46)$ & 1 & & \\
\hline $\begin{array}{l}\text { Maximum ferritin levels }(\mathrm{ng} / \mathrm{mL}) \\
\text { NR 20-400 }\end{array}$ & $1056(300 ; 4372)$ & $361(281 ; 3281)$ & 0.5 & & \\
\hline $\begin{array}{l}\text { Maximum C-reactive protein } \\
(\mathrm{mg} / \mathrm{dL}) \mathrm{NR}<0.4\end{array}$ & $15(4 ; 26)$ & $11(0 ; 20)$ & 0.09 & & \\
\hline $\begin{array}{l}\text { Maximum lactate dehydrogenase } \\
\text { (U/L) NR < } 234\end{array}$ & $367(267 ; 687)$ & $276(198 ; 562)$ & 0.1 & & \\
\hline $\begin{array}{l}\text { Minimum lymphocytes count } \\
\left(1000 / \mathrm{mm}^{3}\right)\end{array}$ & $600(100 ; 1000)$ & $500(200 ; 800)$ & 0.8 & & \\
\hline D-dimer (ng/mL) NR < 500 & $\begin{array}{l}1300(1000 ; \\
12400)\end{array}$ & $1300(500 ; 10000)$ & 1 & & \\
\hline $\begin{array}{l}\text { Number of analytic results in last } \\
\text { tercile }\end{array}$ & $1(1 ; 3)$ & $2(1 ; 3)$ & & 0.6692 & 0.1008 \\
\hline Respiratory insufficiency & $14(74)$ & $5(26)$ & 0.03 & & \\
\hline ICU admission & $6(33)$ & $4(27)$ & 0.7 & & \\
\hline $\begin{array}{l}\text { ICU admission post biologic } \\
\text { infusion }(>24 \mathrm{~h})\end{array}$ & $2(11)$ & - & - & & \\
\hline
\end{tabular}


Table 2. Cont.

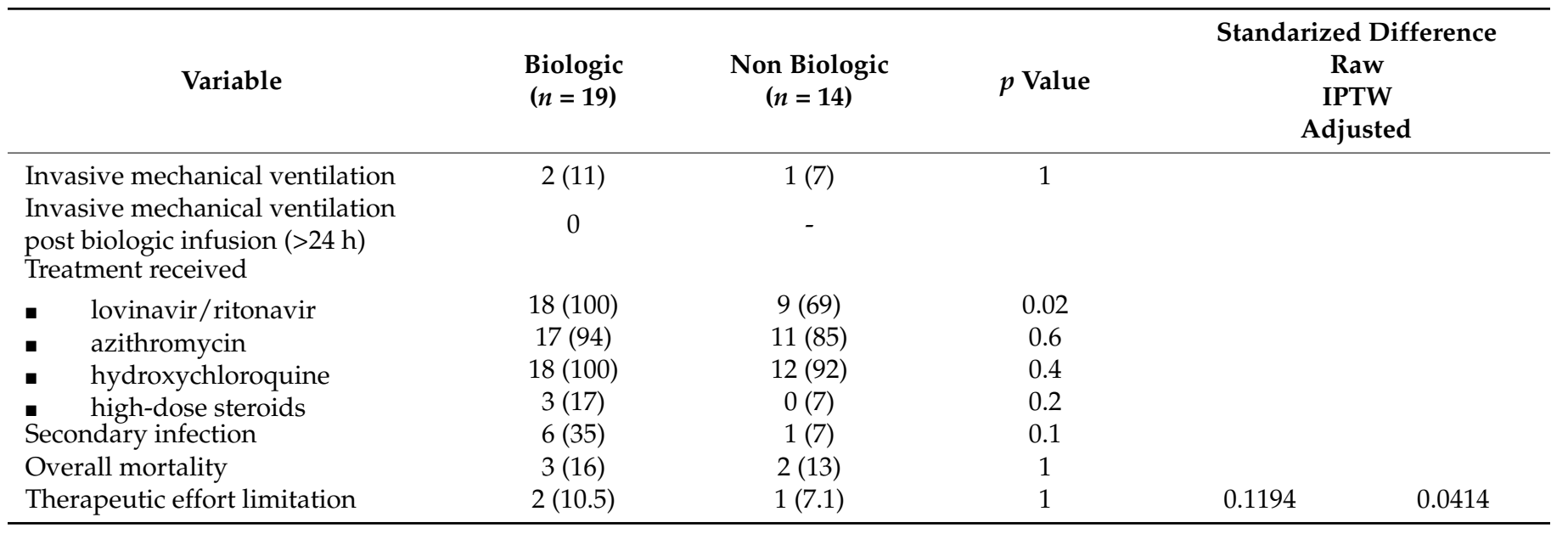

Interquartile range (IQR); ordinary scale determination (OSD); normal range (NR); intensive care unit (ICU).

Seven patients presented a secondary respiratory infection and 3 of them had received both biologic and high dose steroids treatment, 3 only anti-cytokine therapy and the remaining patient received high dose steroids. All infections were of bacterial etiology except one, which was fungal (invasive aspergillosis). Seven patients in our cohort presented a secondary respiratory infection; 3 of them had received both biologic and high dose steroid treatment, 3 had received only anti-cytokine therapy and the remaining patient had received high-dose steroids only. All infections were bacterial with one exception that was fungal (invasive aspergillosis). Four of them required ICU admission, one required extracorporeal membrane oxygenation and 3 of them required non-invasive ventilation. Those admitted to the ICU had additional secondary respiratory infections during their ICU stay. The median number of days from biologic therapy to secondary infection was 10 days (IQR 5-14). All patients survived except one (who needed extracorporeal membrane oxygenation therapy).

Weighted logistic regression analysis by IPTW for outcomes in terms of OSD by biologic prescription is described in Table 3. Use of biologic therapy was associated with a minor probability of a maximum OSD index during hospitalization $\geq 5$ (OR 0.17 (95\%CI: $0.01 ; 3.83)$ ) without initial statistical significance, but after performing simulation by bootstrap, 2.5th and 97.5th percentiles of calculated OR were between 0.10 and 0.72 suggesting a possible statistical association in further studies.

Table 3. Logistic regression analysis with IPTW for outcomes in terms of OSD by biologic prescription.

\begin{tabular}{|c|c|c|c|}
\hline & \multicolumn{2}{|c|}{ Logistic Regression w/IPTW } & $\begin{array}{l}\text { Logistic Regression w/IPTW and } \\
\text { Bootstrap }(n=1000) \text { w/Replacement }\end{array}$ \\
\hline & OR $(95 \% C I)$ & $p$-value & OR (2.5; 97.5 percentiles) \\
\hline $\mathrm{OSD}=7$ & $0.66(0.07 ; 6.60)$ & 0.7254 & $0.75(0.15 ; 2.16)$ \\
\hline OSD during hospitalization $\geq 5$ & $0.17(0.01 ; 3.83)$ & 0.2669 & $0.31(0.10 ; 0.72)$ \\
\hline Maximum OSD $\geq 5$ & $0.41(0.05 ; 3.38)$ & 0.4089 & $0.54(0.11 ; 1.72)$ \\
\hline
\end{tabular}

Ordinary scale determination (OSD).

The weighted analysis was made with an ITPW from a propensity score to (PS) to received biologic from the following parameters: age, sex, number of comorbidities, basal creatinine, number of analytical values in last tercile, prior transplantation, days from symptom onset to test, type of immunosuppressive regimen, baseline OSD and therapeutic effort limitation. Due to the limitation of sample size, a bootstrap resampling $(n=1000)$ with replacement was performed and we presented 2.5th and 97.5th of estimations of OR for these 1000 analyses. 


\section{Discussion}

In this study we analyzed a cohort of kidney transplant recipients and evaluated the impact of anti-cytokine therapies use. Despite being a small sized-cohort; the simulation analysis with a resampling of 1000 samples suggests that it would be possible to conclude, as a hypothesis, a potential beneficial effect of the use of AT in kidney transplant recipients.

Accumulating evidence suggests that the host's immune response and development of tissue-focused inflammation in the lung likely play an important role in COVID-19 pathogenesis [17]. Patients with severe COVID-19 can have a cytokine storm syndrome characterised by increased interleukin (IL)-1, IL-2, IL-6, granulocyte-colony stimulating factor, interferon- $\mathrm{Y}$ inducible protein 10 , macrophage inflammatory protein $1 \alpha$ and tumor necrosis factor (TNF)- $\alpha$ [3] and elevated serum concentrations of Il-1 $\beta$, IL-6 and other inflammatory cytokines; they are are hallmarks of severe forms [18-20]. Elevated serum C-reactive protein, a protein whose expression is driven by IL-6, is also a biomarker of severe infection. In line with this, patients from our study showed high levels of C-reactive protein and ferritin, other parameters that have been associated with the inflammatory cytokine storm related to COVID-19 [19]. We speculated that patients with severe clinical manifestations and elevated laboratory parameters of inflammation could benefit from anti-cytokine therapies, and thus these therapies were introduced in our centre protocol for selected patients.

Tocilizumab was the most frequently prescribed biologic drug in this group of patients. It is a recombinant humanized anti-IL-6 receptor monoclonal antibody which is approved for the treatment in rheumatologic diseases [21]. Additionally, it has been used in some cases of chimeric antigen receptor (CAR) T-cell therapy induced cytokine storm and secondary encephalopathy with favourable outcomes [22]. In kidney transplantation, tocilizumab has been used as rescue therapy in patients with chronic antibodymediated rejection (ABMR) who failed standard-of-care treatment with no significant adverse events [23]. Recent studies have found a beneficial effect of tocilizumab in reducing mortality, need for mechanical ventilation and shortening hospitalization [24,25], however, other studies found no benefit in the use of tocilizumab [26]. Anakinra, the second most frequently prescribed biologic treatment in this group of patients, is an IL-1 receptor antagonist with a very safe profile [27]. It is the cornerstone treatment for hyperinflammatory conditions such as Still's disease, and also has been shown to be highly effective in the treatment of cytokine storm syndromes, including macrophage activation syndrome and cytokine release syndrome [28]. It has been used as a safe and effective therapeutic option for gout in patients with chronic kidney disease [29]. In a non-SOT population presenting with COVID-19, anakinra had shown promising results [30-32]. Finally, baricitinib is a small molecule, orally administered, JAK- 1 and -2 selective inhibitor used in patients with moderate or severe rheumatoid arthritis or patients with other active disease-modifying antirheumatic drugs with inadequate responses to prior therapies [33]. Studies evaluating the use of baricitinib as COVID-19 therapy are still ongoing and preliminary results showed potential benefits [34].

We found that the mortality rate of kidney transplant-recipients was similar to that of non-SOT patients [35] and similar to other cohorts of COVID-19 SOT patients [8,9]. One could expect some protective effect of immunosuppressive therapies from the inflammatory storm or even due to the in vitro activity shown by some drugs such as cyclosporine, tacrolimus and mTOR inhibitors [18]. However, median years from transplantation to COVID-19 in our study were 5.5, which was not in the peak period of immunosupression and moreover, calcineurin inhibitors and mTOR inhibitors were mostly suspended during hospitalization due to drug interactions with lopinavir/ritonavir.

The strengths of this clinical study are that the cohort included all cases of COVID-19 kidney transplant recipients during the study period that received AT with promising results. However, it has some limitations. First of all, as it is a single-centre study, our findings may be attributable to institution-specific variables and may not reflect the epidemiology of different centers and/or geographical areas. Secondly, the size of this cohort is too small to 
draw strong conclusions and, therefore, randomized controlled trials evaluating the impact of the use biologic treatments in immunosuppressed patients are imperative. Furthermore, the real incidence of SARS-CoV-2 infection in the SOT population is unknown and we might be underestimating the real impact. Nonetheless, all kidney transplant recipients are periodically and closely followed-up, even during the pandemic period. We are planning to perform serologic tests in all recipients to make a better estimate of the real incidence of SARS-CoV-2 infection in this population. Finally and importantly, the study was performed during the first wave of the COVID-19 pandemic, and the standard of care treatment has changed since then as several randomized trials have shown the benefit of some drugs such as remdesivir and dexamethasone [36-38], which are currently used.

\section{Conclusions}

To conclude, we found that the use of AT in our cohort of kidney transplant recipients was safe and responses, in terms of clinical efficacy using the OSD score, were favorable. However, independent studies in order to confirm these findings and randomized clinical trials evaluating the impact of using AT in SOT recipients over the long term are needed.

Author Contributions: Conceptualization, M.B. and F.C.; methodology, M.B., F.C. and J.R.; software, J.R.; validation, M.B., F.C. and J.R.; formal analysis, J.R.; investigation, M.B. and L.L.; resources, M.B., F.C. and L.L.; data curation, M.B.; writing—original draft preparation, M.B and F.C.; writing-review and editing, S.H., L.L., M.A.M., A.S., A.M. and F.D. All authors have read and agreed to the published version of the manuscript.

Funding: This work was supported by the Fondo Europeo de Desarrollo Regional (FEDER). Unión Europea. "Una manera de hacer Europa". Spanish Network for the Research in Infectious Diseases (REIPI) from the Instituto de Salud Carlos III, Madrid, Spain.

Institutional Review Board Statement: The Institutional Ethics Committee of the Hospital Clínic of Barcelona, approved the study and due to the nature of retrospective chart review, waived the need for informed consent from individual patients (Comité Ėtic d'Investigació Clínica; HCB/2020/0273). All patients signed an informed consent for therapies off-label use.

Informed Consent Statement: Informed consent was obtained from all subjects involved in the study.

Data Availability Statement: Data supporting these results is available under request.

Conflicts of Interest: The authors declare no conflict of interest.

\section{References}

1. World Health Organization. Coronavirus Disease 2019 (COVID-19) Situation Report [online]. Available online: https: //www.who.int/docs/default-source/coronaviruse/situation-reports/20200304-sitrep-44-covid-19.pdf?sfvrsn=783b4c9d_6 (accessed on 5 February 2021).

2. Wu, Z.; McGoogan, J.M. Characteristics of and Important Lessons From the Coronavirus Disease 2019 (COVID-19) Outbreak in China. JAMA 2020, 323, 1239-1242. [CrossRef]

3. Huang, C.; Wang, Y.; Li, X.; Ren, L.; Zhao, J.; Hu, Y.; Zhang, L.; Fan, G.; Xu, J.; Gu, X.; et al. Clinical features of patients infected with 2019 novel coronavirus in Wuhan. China. Lancet 2020, 395, 497-506. [CrossRef]

4. Guan, W.J.; Ni, Z.Y.; Hu, Y.; Liang, W.H.; Ou, C.Q.; He, J.X.; Liu, L.; Shan, H.; Lei, C.L.; Hui, D.S.; et al. Clinical Characteristics of Coronavirus Disease 2019 in China. N. Engl. J. Med. 2020, 382, 1708-1720. [CrossRef]

5. Mehta, P.; McAuley, D.F.; Brown, M.; Sanchez, E.; Tattersall, R.S.; Manson, J.J. COVID-19: Consider cytokine storm syndromes and immunosuppression. Lancet 2020, 395, 1033-1034. [CrossRef]

6. Richardson, P.; Griffin, I.; Tucker, C.; Smith, D.; Oechsle, O.; Phelan, A.; Stebbing, J. Baricitinib as potential treatment for 2019-nCoV acute respiratory disease. Lancet 2020, 395, e30-e31. [CrossRef]

7. Fernández-Ruiz, M.; Andrés, A.; Loinaz, C.; Delgado, J.F.; López-Medrano, F.; San Juan, R.; González, E.; Polanco, N.; Folgueira, M.D.; Lalueza, A.; et al. COVID-19 in solid organ transplant recipients: A single-center case series from Spain. Am. J. Transplant. 2020, 20, 1849-1858. [CrossRef] [PubMed]

8. Pereira, M.R.; Mohan, S.; Cohen, D.J.; Husain, S.A.; Dube, G.K.; Ratner, L.E.; Arcasoy, S.; Aversa, M.M.; Benvenuto, L.J.; Dadhania, D.M.; et al. COVID-19 in Solid Organ Transplant Recipients: Initial Report from the US Epicenter. Am. J. Transplant. 2020, 20, 1800-1808. [CrossRef] [PubMed] 
9. Tschopp, J.; L'Huillier, A.G.; Mombelli, M.; Mueller, N.J.; Khanna, N.; Garzoni, C.; Meloni, D.; Papadimitriou-Olivgeris, M.; Neofytos, D.; Hirsch, H.H.; et al. First experience of SARS-CoV-2 infections in solid organ transplant recipients in the Swiss Transplant Cohort Study. Am. J. Transplant. 2020, 20, 2876-2886. [CrossRef] [PubMed]

10. Caillard, S.; Anglicheau, D.; Matignon, M.; Durrbach, A.; Greze, C.; Frimat, L.; Thaunat, O.; Legris, T.; Moal, V.; Westeel, P.F.; et al. An initial report from the French SOT COVID Registry suggests high mortality due to COVID-19 in recipients of kidney transplants. Kidney Int. 2020, 98, 1549-1558. [CrossRef]

11. Cravedi, P.; Mothi, S.S.; Azzi, Y.; Haverly, M.; Farouk, S.S.; Pérez-Sáez, M.J.; Redondo-Pachón, M.D.; Murphy, B.; Florman, S.; Cyrino, L.G.; et al. COVID-19 and kidney transplantation: Results from the TANGO International Transplant Consortium. Am. J. Transplant. 2020, 20, 3140-3148. [CrossRef] [PubMed]

12. Akalin, E.; Azzi, Y.; Bartash, R.; Seethamraju, H.; Parides, M.; Hemmige, V.; Ross, M.; Forest, S.; Goldstein, Y.D.; Ajaimy, M.; et al. Covid-19 and Kidney Transplantation. N. Engl. J. Med. 2020, 382, 2475-2477. [CrossRef] [PubMed]

13. Bellomo, R.; Ronco, C.; Kellum, J.A.; Mehta, R.L.; Palevsky, P. Acute renal failure-Definition, outcome measures, animal models, fluid therapy and information technology needs: The Second International Consensus Conference of the Acute Dialysis Quality Initiative (ADQI) Group. Crit. Care 2004, 8, R204-R212. [CrossRef] [PubMed]

14. Austin, P.C. An introduction to propensity score methods for reducing the effects of confounding in observational studies. Multivar. Behav. Res. 2011, 46, 399-424. [CrossRef] [PubMed]

15. Austin, P.C. Balance diagnostics for comparing the distribution of baseline covariates between treatment groups in propensityscore matched samples. Stat. Med. 2009, 28, 3083-3107. [CrossRef]

16. Dempster, A.P.; Laird, N.M.; Rubin, D.B. Maximum Likelihood from Incomplete Data Via the EM Algorithm. J. R. Stat. Soc. Ser. B. Epub. 1977, 39, 1-22.

17. Henderson, L.A.; Canna, S.W.; Schulert, G.S.; Volpi, S.; Lee, P.Y.; Kernan, K.F.; Caricchio, R.; Mahmud, S.; Hazen, M.M.; Halyabar, O.; et al. On the alert for cytokine storm: Immunopathology in COVID-19. Arthritis Rheumatol. 2020, 72, 1059-1063. [CrossRef]

18. Moore, B.J.B.; June, C.H. Cytokine release syndrome in severe COVID-19. Science 2020, 368, 473-474. [CrossRef]

19. Chen, G.; Wu, D.I.; Guo, W.; Cao, Y.; Huang, D.; Wang, H.; Wang, T.; Zhang, X.; Chen, H.; Yu, H.; et al. Clinical and immunological features of severe and moderate coronavirus disease 2019. J. Clin. Investig. 2020, 130, 2620-2629. [CrossRef]

20. Pedersen, S.F.; Ho, Y.C. SARS-CoV-2: A storm is raging. J. Clin. Investig. 2020, 130, 2202-2205. [CrossRef]

21. Sheppard, M.; Laskou, F.; Stapleton, P.P.; Hadavi, S.; Dasgupta, B. Tocilizumab (actemra). Hum. Vaccines Immunother. 2017, 13, 1972-1988. [CrossRef]

22. Brudno, J.N.; Kochenderfer, J.N. Recent advances in CAR T-cell toxicity: Mechanisms, manifestations and management. Blood Rev. 2019, 34, 45-55. [CrossRef]

23. Choi, J.; Aubert, O.; Vo, A.; Loupy, A.; Haas, M.; Puliyanda, D.; Kim, I.; Louie, S.; Kang, A.; Peng, A.; et al. Assessment of Tocilizumab (Anti-Interleukin-6 Receptor Monoclonal) as a Potential Treatment for Chronic Antibody-Mediated Rejection and Transplant Glomerulopathy in HLA-Sensitized Renal Allograft Recipients. Am. J. Transplant. 2017, 17, 2381-2389. [CrossRef]

24. Hermine, O.; Mariette, X.; Tharaux, P.L.; Resche-Rigon, M.; Porcher, R.; Ravaud, P. Effect of Tocilizumab vs Usual Care in Adults Hospitalized with COVID-19 and Moderate or Severe Pneumonia: A Randomized Clinical Trial. JAMA 2021, $181,32-40$. Available online: https://pubmed.ncbi.nlm.nih.gov/33080017/ (accessed on 18 March 2021).

25. Salama, C.; Han, J.; Yau, L.; Reiss, W.G.; Kramer, B.; Neidhart, J.D.; Criner, G.J.; Kaplan-Lewis, E.; Baden, R.; Pandit, L.; et al. Tocilizumab in Patients Hospitalized with Covid-19 Pneumonia. N. Engl. J. Med. 2021, 384, 20-30. [CrossRef]

26. Stone, J.H.; Frigault, M.J.; Serling-Boyd, N.J.; Fernandes, A.D.; Harvey, L.; Foulkes, A.S.; Horick, N.K.; Healy, B.C.; Shah, R.; Bensaci, A.M.; et al. Efficacy of Tocilizumab in Patients Hospitalized with Covid-19. N. Engl. J. Med. 2020, 383, $2333-2344$. Available online: https:/ / pubmed.ncbi.nlm.nih.gov/33085857/ (accessed on 18 March 2021). [CrossRef]

27. Fleischmann, R.M.; Schechtman, J.; Bennett, R.; Handel, M.L.; Burmester, G.R.; Tesser, J.; Modafferi, D.; Poulakos, J.; Sun, G. Anakinra, a recombinant human interleukin-1 receptor antagonist (r-metHuIL-1ra), in patients with rheumatoid arthritis: A large, international, multicenter, placebo-controlled trial. Arthritis Rheum. 2003, 48, 927-934. [CrossRef]

28. La Rosée, P.; Horne, A.; Hines, M.; von Bahr Greenwood, T.; Machowicz, R.; Berliner, N.; Birndt, S.; Gil-Herrera, J.; Girschikofsky, M.; Jordan, M.B.; et al. Recommendations for the management of hemophagocytic lymphohistiocytosis in adults. Blood 2019, 133, 2465-2477. [CrossRef]

29. Loustau, C.; Rosine, N.; Forien, M.; Ottaviani, S.; Juge, P.A.; Lioté, F.; Bardin, T.; Richette, P.; Dieudé, P.; Richez, C.; et al. Effectiveness and safety of anakinra in gout patients with stage 4-5 chronic kidney disease or kidney transplantation: A multicentre, retrospective study. Jt. Bone Spine 2018, 85, 755-760. [CrossRef]

30. Day, J.W.; Fox, T.A.; Halsey, R.; Carpenter, B.; Kottaridis, P.D. IL-1 blockade with anakinra in acute leukaemia patients with severe COVID-19 pneumonia appears safe and may result in clinical improvement. Br. J. Haematol. 2020, 190, e80-e83. [CrossRef]

31. Filocamo, G.; Mangioni, D.; Tagliabue, P.; Aliberti, S.; Costantino, G.; Minoia, F.; Bandera, A. Use of anakinra in severe COVID-19: A case report. Int. J. Infect Dis. 2020, 96, 607-609. [CrossRef]

32. Franzetti, M.; Pozzetti, U.; Carugati, M.; Pandolfo, A.; Molteni, C.; Faccioli, P.; Castaldo, G.; Longoni, E.; Ormas, V.; Iemoli, E.; et al. Interleukin-1 receptor antagonist anakinra in association with remdesivir in severe Coronavirus disease 2019: A case report. Int. J. Infect Dis. 2020, 97, 215-218. [CrossRef] 
33. Fleischmann, R.; Schiff, M.; van der Heijde, D.; Ramos-Remus, C.; Spindler, A.; Stanislav, M.; Zerbini, C.A.; Gurbuz, S.; Dickson, C.; de Bono, S.; et al. Baricitinib, Methotrexate, or Combination in Patients With Rheumatoid Arthritis and No or Limited Prior Disease-Modifying Antirheumatic Drug Treatment. Arthritis Rheumatol. 2017, 69, 506-517. [CrossRef]

34. Cantini, F.; Niccoli, L.; Matarrese, D.; Nicastri, E.; Stobbione, P.; Goletti, D. Baricitinib therapy in COVID-19: A pilot study on safety and clinical impact. J. Infect. 2020, 81, 318-356. [CrossRef]

35. Richardson, S.; Hirsch, J.S.; Narasimhan, M.; Crawford, J.M.; McGinn, T.; Davidson, K.W.; Barnaby, D.P.; Becker, L.B.; Chelico, J.D.; Cohen, S.L.; et al. Presenting Characteristics, Comorbidities, and Outcomes Among 5700 Patients Hospitalized With COVID-19 in the New York City Area. JAMA 2020, 323, 2052-2059. [CrossRef]

36. Spinner, C.D.; Gottlieb, R.L.; Criner, G.J.; López, J.R.A.; Cattelan, A.M.; Viladomiu, A.S.; Ogbuagu, O.; Malhotra, P.; Mullane, K.M.; Castagna, A.; et al. Effect of Remdesivir vs Standard Care on Clinical Status at 11 Days in Patients with Moderate COVID-19: A Randomized Clinical Trial. JAMA 2020, 324, 1048-1057. [CrossRef]

37. Tomazini, B.M.; Maia, I.S.; Cavalcanti, A.B.; Berwanger, O.; Rosa, R.G.; Veiga, V.C.; Avezum, A.; Lopes, R.D.; Bueno, F.R.; Silva, M.V.A.; et al. Effect of Dexamethasone on Days Alive and Ventilator-Free in Patients with Moderate or Severe Acute Respiratory Distress Syndrome and COVID-19: The CoDEX Randomized Clinical Trial. JAMA 2020, 324, 1307-1316. [CrossRef]

38. Sterne, J.A.; Murthy, S.; Diaz, J.V.; Slutsky, A.S.; Villar, J.; Angus, D.C.; Annane, D.; Azevedo, L.C.P.; Berwanger, O.; Cavalcanti, A.B.; et al. Association between Administration of Systemic Corticosteroids and Mortality among Critically Ill Patients with COVID-19: A Meta-analysis. JAMA 2020, 324, 1330-1341. 